\title{
Development of a new lining ball mill model for commercial component preservation
}

\author{
Ivan Lebedev ${ }^{1 *}$ \\ ${ }^{1}$ Mining Institute of the North named after N.V. Chersky, SB RAS, Laboratory of Mineral \\ Processing, 43 Lenin Av., Yakutsk, 678980, Russian Federation
}

\begin{abstract}
At present the main aggregates for fine grinding of gold ores are ball and similar mills, in which in addition to mass ore grinding, deformation and free gold destruction occurs. The article aims to study the process of deformation of free gold extracted during grinding and to develop a ball mill design to preserve the commercial component.

Keywords. Grinding, gold, mineral disclosure, gold regrinding, riffles, ball mill, gold extraction, particle isometrization.
\end{abstract}

\section{Introduction}

The work is stipulated by a general tendency to reduce energy consumption per unit of output. The current level of the society technical development and inevitable growth of energy consumption in the future on the one hand and limited energy resources on the other hand, along with the search for new types of energy, leads to the need to develop energysaving technologies in all areas of production.

Preparation for ores benefication is one of the most energy intensive and cost processes in mineral processing technology. In that regard, a number of studies, being the basic theory and practice of minerals processing preparing, have been carried out.

Some domestic and foreign scientists are considered to be the founders of the modern ore preparation theory. Among them there are such researchers as S.E. Andreev, N.P. Neronov, K.A. Razumov, V.A. Olevskiy, V.A. Perov, F. Bond, Hardgrove and others. The majority of researches are devoted to studying the laws of disintegration and classification of mineral processing products by size in various points of technological schemes. However, at present, the literature does not sufficiently cover the issues of quantitative and qualitative assessment of the energy consumed distribution during ore processing between technological operations. Absence of criteria for efficiency assessment of certain types of equipment for ore processing complex leads not only to increased energy costs, but also to under-extraction of commercial component and higher consumption of engineering materials.

The main idea of the work is to develop an effective ball mill lining for rational distribution of energy costs for formation of a new surface at the minerals disintegration

\footnotetext{
* Corresponding authors: ivleb@mail.ru
} 
stages, without regrinding of the disclosed material, many scientists were involved in this [1-4].

The main aim of the work is to create a theoretical basis for assessment of free gold transformation during minerals disintegration in the ball mill and to develop its new design based on the studies of gold particles deformation mechanism.

\section{Procedure}

It was found experimentally that the specificity of gold grains structure in a torus form was a result of microforging (bombardment) of the gold grain edges with sand grains moved by the air flow [5]. This occurs as a result of a significant lag of gold movement from the sand grains moved by the air flow.

For example, any plate with a proportional width and length, as a result of isotropic bombardment over a period of time tends to take a torus form, the inner part of it holds a flat shape.

On the basis of the experimental researches of a tore formation process, its simulation model was worked out, it makes it possible to calculate a time interval at which the torus maximal size is formed, and unload the commercial component without being over-crushed in a mill.

A review of publications showed that the researchers were mainly engaged in improving the mill linings, but so far, there are no solutions that have radically changed the issue of heavy minerals preservation in the process of their release from ore in ball mills [6]. We have developed a new design of a ball mill with spiral groove for timely removing and preservation of the commercial component, which is shown in Figure 1 [7].

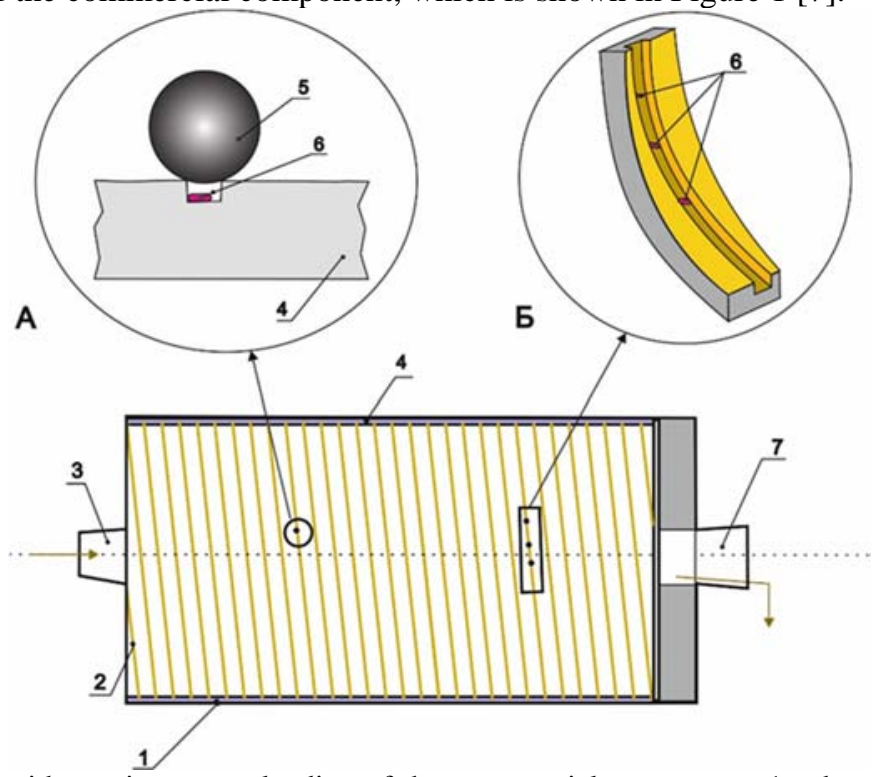

Fig.1. Ball mill with continuous unloading of the commercial component: 1 - drum; 2 - riffles; 3 loading spout, 4 - armor, 5 - grinding unit, 6 - commercial component, 7 - unloading spout. A fragment of armor with riffles and grinding unit (ball), B - fragment of riffle with commercial component.

The mode of the mill is as follows. Water and ore are fed into the mill operating cavity through a loading spout. In the process of ore fragments destruction, high density particles of commercial components seep onto the lining surface and get into the grooves - riffles on 
the armor plates in the form of a screw thread. From this point on, the heavy particles are inaccessible to the grinding balls and are not deformed.

For the laboratory model of the ball mill, a thick-walled tube with a diameter of $400 \mathrm{~mm}$ with screwed riffles sawn by a side grinder was used (Fig. 2).

Fig.2. Spiral riffles marking out and sawing.
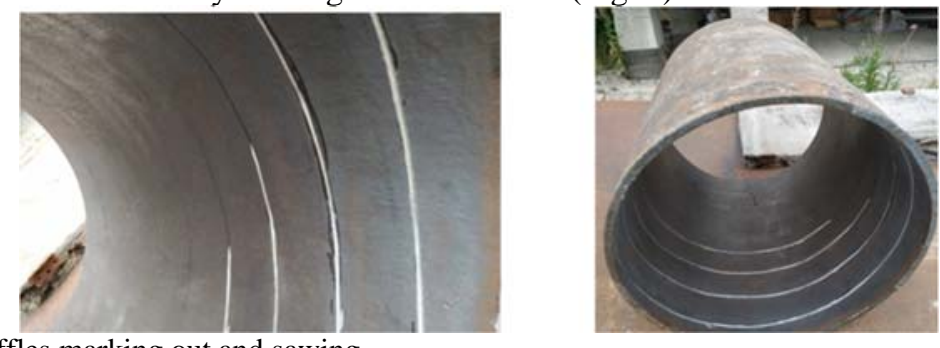

A general view of the laboratory ball mill is presented in Fig. 3, with the inner side riffles in the form of spiral grooves for preservation and removal of commercial components from the destruction zone, with the inner drum diameter $-0.40 \mathrm{~m}$ and length $0.50 \mathrm{~m}[2]$.
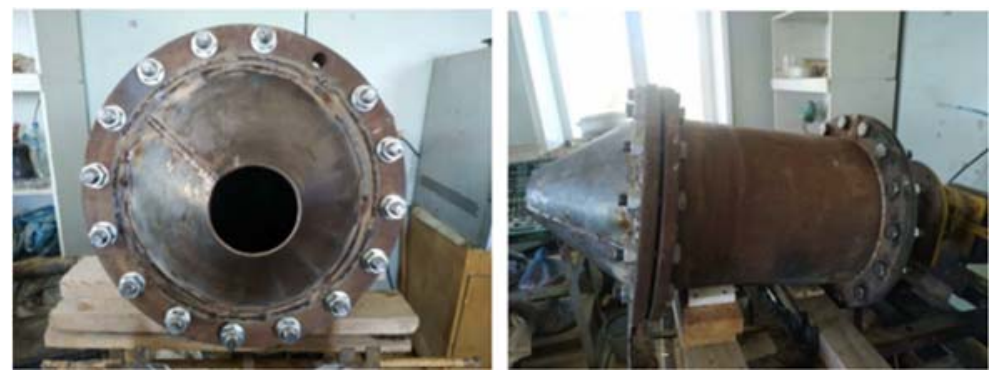

Fig. 3. General view of laboratory ball mill with grooves as spiral riffles.

If necessary, the mill can be operated in an inclined position up to 20 degrees of gradient. The drum speed is $20 \mathrm{rpm}$, which corresponds to the mill. cascade mode. The volume of the working cavity is $0.07 \mathrm{~m}^{3}$. The diameter of the working balls varies from 5 to $12 \mathrm{~cm}$. The balls are loaded for the volume of a grinding chamber at 50-55\%. Quartz ore with $3 \mathrm{~mm}$ particle size was used as the initial crushed sample. The volume of a single sample was $15 \mathrm{~kg}$. The mill was loaded in both "wet" and "dry" grinding mode.

\section{Experimental studies}

During the experimental study, the lead markers were used as gold simulators, as they have high enough density and ductility. The number of markers was from 200 to 500 particles. The coarseness of the particle was about $3 \mathrm{~mm}$; the thickness - $0.5 \mathrm{~mm}$. After each cycle, the markers were removed and their morphological change peculiarities were studied during the mill operation. The granular composition of the markers also changed along with the change of the grain-size distribution of the debris (Fig. 4). 


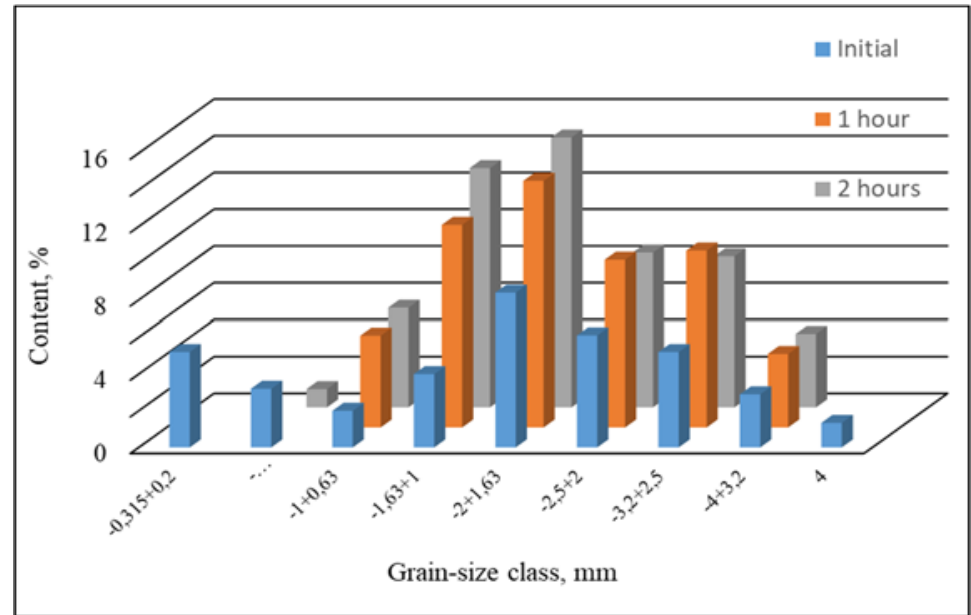

Fig.4. Marker grain size distribution after certain mill operation intervals in horizontal position.

It was found that the markers undergo three main types of deformation: flattening, bending, twisting. The scales deformation in the form of U-shape or roll twisting, as well as thickening of the scales edges is noted separately.

Flattening of the markers is observed during the first hours of the mill operation immediately.

Flattening of the markers indicates that, due to their high density, they are submerged on the bottom of the mill cavity and move flat around the mill. The mill balls are rolled over them and roll them into plates and scales.

During grinding, the markers fall into the "saltation" (tumbling, flipping-over) zone of particles around their axis and sought to have a rounded shape. Thanks to spiral grooves, the markers could not be flattened or crumbled again, but acquired more spherical shapes and removed from grinding process.

\section{Conclusion}

Eventually, thanks to the new mill design with grooves as spiral riffles, the gold grains are subjected to much less contact with grinding units and waste rock, are preserved and removed from the destruction zone, which will increase the commercial components recovery.

The work was performed under the Grant of Russian Foundation for Basic Research 1845-140036 r_a

\section{References}

1. M. Rodrigo, C. Luís, M. Tavares, Minerals Engineering, 43-44, 91-101 (2003)

2. R. Schnatz, International Journal of Mineral Processing, 74, 55-63 (2004)

3. J. Yang, S. Li, C. Xi-Song, Q. Li, Powder Technology, 198, 219-228 (2010)

4. M. Abdellaoui, E. Gaffet, Journal of Process Control, 15, 273-283 (2005)

5. V. E. Filippov, Z. S. Nikiforova, Siberian Enterprise of the Russian Academy of Science (1998)

6. E. Klas-Goran, M. Gunder, A.L. Grebenshchikov, V.Yu. Fishev, Mining Industry, 1, 24$58(2003)$

7. D. A. Osipov, V. E. Filippov, Mining Information and Analytical Bulletin, 11, 223-228 